\title{
TINJAUAN KARAKTERISTIK TANAH UNTUK STABILISASI LAPIS PONDASI PERKERASAN JALAN
}

\author{
Bambang Raharmadi \\ Teknik Jalan dan Jembatan Ahli Muda \\ Direktorat Jenderal Bina Marga \\ Kementerian Pekerjaan Umum dan Perumahan Rakyat
}

\begin{abstract}
ABSTRAK
Dalam pembangunan jalan sering kali terjadi tidak tersedianya sumberdaya alam yang memenuhi syarat di lokasi pekerjaan, terutama batu pecah untuk pondasi perkerasan jalan yang harus didatangkan dari luar daerah, yang akan mengakibatkan biaya konstruksi menjadi tinggi. Untuk mengatasi hal tersebut di atas, sebagai konstruksi alternatif adalah dengan memanfaatkan material lokal yang perlu dilakukan perbaikan sifat-sifat fisik dan mekanik tanah lokal dari sumber quari yang akan di gunakan sebagai material stabilisasi dengan semen harus memenuhi syarat yang diijinkan.

Prosedur yang dilakukan adalah pengujian sifat-sifat fisik dan mekanik tanah dari quari desa Bukit Batu dan quari dusun Manyawang berdasarkan Standar Nasional Indonesia (SNI).

Tujuan dari penyusunan makalah ini adalah untuk mengetahui sifat-sifat fisik dan mekanik tanah dari quari desa Bukit Batu dan quari dusun Manyawang agar bisa digunakan sebagai bahan stabilisasi semen

Hasil uji material tanah quari desa Bukit Batu sedalam 1,5 meter dari muka tanah dengan warna tanah kuning kecoklatan, kadar air 14,34\%, berat jenis 2,637 dan quari dusun Manyawang 1,25 meter dari muka tanah dengan warna tanah kuning kecoklatan, kadar air 13,80\%, berat jenis 2,635. Uji distribusi ukuran butir memenuhi syarat yang diijinkan untuk digunakan sebagai material stabilisasi tanah semen dengan indek plastisitas $5,41 \%, 6,21 \% \leq 10 \%$ syarat yang ditentukan (Hicks,2002) dan klasifikasi tanah sistem USCS termasuk pada kelompok CL-ML yaitu lanau tak organik, lempung kepasiran dengan plastisitas rendah dan AASHTO termasuk pada kelompok A-4 yaitu lempung lanau dengan plastisitas rendah. Uji pemadatan ringan (standart) quari desa Bukit Batu isi kering maksimum $\left(\gamma_{\mathrm{dmax}}\right)$ dari tanah $1,860 \mathrm{t} / \mathrm{m}^{3}$, kadar air optimum 13,30\% dan Manyawang berat berat isi kering maksimum $\left(\gamma_{\mathrm{dmax}}\right)$ dari tanah1,860 $\mathrm{t} / \mathrm{m}^{3}$, kadar air optimum 13,30\%. Uji kuat tekan bebas (UCS) quari desa Bukit Batu dan Manyawang 3,451 kg/ $\mathrm{cm}^{2}, 3,521$ $\mathrm{kg} / \mathrm{cm}^{2}$ dan uji CBR quari desa Bukit Batu dan Manyawang CBR ${ }_{100} 9,40 \%, 8,10 \%$ dan CBR $95 \quad 5,20 \%$, $4,65 \%$.
\end{abstract}

\section{Kata Kunci : Karakteristik Tanah, stabilisasi, pondasi perkerasan jalan}


Tinjauan Karakterisik Tanah untuk Stabilisasi..., Bambang Raharmadi

\section{PENDAHULUAN}

\section{Latar Belakang}

Jalan sebagai sistem transportasi nasional mempunyai peranan penting terutama dalam mendukung bidang ekonomi, sosial dan budaya serta lingkungan agar tercapai keseimbangan dan pemerataan pembangunan antar daerah, membentuk dan memperkokoh kesatuan nasional, memantapkan pertahanan dan keamanan nasional serta membentuk struktur ruang dalam rangka mewujudkan sasaran pembangunan nasional.

Dalam pembangunan jalan sering kali terjadi tidak tersedianya sumberdaya alam yang memenuhi syarat di lokasi pekerjaan, terutama batu pecah untuk pondasi perkerasan jalan yang harus didatangkan dari luar daerah, yang akan mengakibatkan biaya konstruksi menjadi tinggi.

Untuk mengatasi hal tersebut di atas, sebagai konstruksi alternatif adalah dengan memanfaatkan material lokal yang perlu dilakukan perbaikan sifat-sifat fisik dan mekanik tanah lokal dari quari desa Bukit Batu dan quari dusun Manyawang yang akan di gunakan sebagai material stabilisasi dengan semen harus memenuhi syarat yang diijinkan. Menurut Porland Cement Association (1979), mensyaratakan tanah yang distabilisasi dengan semen sebaiknya tanah-tanah berpasir dan berkerikil, dan Hicks (2002), distribusi ukuran butir dan batas-batas Atterberg digunakan sebagai dasar penilaian macam stabilisasi dengan PI $\leq$ 10\%. Perbaikan sifat-sifat mekanik tanah dengan menembah semen untuk dimaksudkan meningkatkan kekuatan tanah lokal agar memenuhi persyaratan Spesifikasi Umum 2010 (revisi 3), nilai kuat tekan bebas (UCS) target adalah $\geq 24 \mathrm{~kg} / \mathrm{cm}^{2}$ dengan umur pemeraman 7 hari (SNI 03-6887-2002) dan nilai $C B R$ target adalah $\geq 120 \%$ dengan umur pemeraman 3 hari dan perendaman 4 hari (SNI 03-3438-1994) sebagai lapis pondasi perkerasan. Usaha perbaikan tanah itu disebut stabilisasi tanah dengan cara mekanis atau dengan menambah suatu bahan tambah (semen).

Dengan menggunakan stabilisasi tanah lokal dengan semen ini di harapkan dapat membantu mengatasi salah satu permasalah dalam pembangunan jalan.

\section{Perumusan Masalah}

Makalah ini lebih di fokuskan untuk untuk mengetahui sifat-sifat fisik dan mekanik tanah.

\section{Tujuan Penelitian}

Tujuan dari penyusunan makalah ini adalah untuk mengetahui sifat-sifat fisik dan mekanik tanah agar bisa digunakan sebagai bahan stabilisasi semen

\section{Manfaat Penelitian}

Dengan melakukan penyusunan makalah ini diharapkan dapat bermanfaat dan berguna, baik secara teoritis maupun praktis, yaitu :

a. Secara teoritis

1. Mengetahui sifat-sifat fisik dan mekani tanah lokal quari desa Bukit Batu dan dusun Manyawang.

2. Menambah pengetahuan tentang sifat-sifat fisik dan mekanik tanah yang bisa digunakan sebagai bahan stabilisasi dengan semen.

3. Menambah bahan rujukan yang dapat dijadikan penyusunan makalah lebih lanjut.

b. Secara praktis

1. Hasil penyusunan makalah ini diharapkan dapat bermanfaat dalam pembangunan jalan yang mengalami kesulitan untuk pengadaan material batu pecah dan sebagai bahan pertimbangan pekerjaan selanjutnya.

2. Sebagai alternatif bahan pengganti lapis pondasi batu pecah sebagai bahan perkerasan jalan yang mungkin dapat lebih menguntungkan dari segi konstruksi dan waktu.

\section{KAJIAN PUSTAKA}

\section{Landasan Teori}

\section{Sifat-sifat Fisik Tanah}

Sifat-sifat fisik tanah (Soil Properties) meliputi ukuran butiran tanah, warnanya, bentuk butiran, dan kekerasan tanah, sedangkan tanah sebagai bahan yang terdiri dari agregat mineralmineral padat yang tidak terikat secara kimia antara satu sama lain dari bahan-bahan organik yang telah melapuk yang berpartikel padat disertai dengan zat cair dan gas yang mengisi ruang-ruang kosong diantara partikel partikel padat tersebut (Das, 2008).

a. Pengujian Distribusi Ukuran Butir

Distribusi ukuran butir adalah pengelompokan besar butir analisa agregat kasar dan agregat halus menjadi komposisi gabungan yang 
ditinjau berdasarkan saringan. Menurut Spesifikasi Umum 2010, revisi 3 adalah tanah yang cocok digunakan untuk lapis pondasi semen tanah harus sesuai dengan ukuran partikel yang ditentukan yaitu ukuran yang paling besar dari partikel batu harus lebih kecil dari $75 \mathrm{~mm}$ dan kurang dari 50\% melewati saringan No. 200 dengan cara pengayakan basah. Porland Cement Association (1979), mensyaratakan tanah yang distabilisasi dengan semen sebaiknya tanah-tanah berpasir dan berkerikil dengan gradsi ukuran butir seperti pada Tabel 2.1 sebagai berikut :

Tabel 2.1 Gradasi Ukuran Butir Tanah Semen

\begin{tabular}{|lc|c|}
\hline \multicolumn{2}{|c|}{ Ukuran Saringan } & $\begin{array}{c}\text { Persen Berat Yang Lolos Saringan } \\
\text { Lapis Pondasi Semen Tanah }\end{array}$ \\
\hline \hline 2" & $(50,00 \mathrm{~mm})$ & 100 \\
No. 4 & $(4,750 \mathrm{~mm})$ & $\geq 55$ \\
No. 10 & $(2,000 \mathrm{~mm})$ & $\geq 37$ \\
No. 200 & $(0,075 \mathrm{~mm})$ & $10-35$ \\
\hline
\end{tabular}

Sumber : Hardiyatmo (2010)

Sistem klasifikasi tanah yang biasa digunakan pekerjaan teknik sipil adalah sebagai berikut :

- Sistem Klasifikasi Tanah Berdasarkan Unified Soil Classification System (USCS). Sistem ini diperkenalkan oleh Cassagrande tahun 1942 yang selanjutnya disempurnakan oleh Unites States Bureau Of Reclamation (USBR) tahun 1952. Sistem ini mengelompokkan tanah dalam dua kelompok besar, yaitu:

a. Tanah Berbutir Kasar ( coarse-grainedsoil ), yaitu: tanah kerikil dan pasir dimana kurang dari $50 \%$ berat total contoh tanah lolos saringan nomer 200. Simbol kelompok ini adalah :

$G=$ untuk tanah berkerikil (Gravel)

$S=$ untuk tanah berpasir (sand)

$W=$ untuk tanah bergradasi baik (well graded)

$P=$ untuk tanah bergradasi buruk (poorly graded)

b. Tanah Berbutir Halus (fine-grained-soil), yaitu tanah dimana lebih dari $50 \%$ berat total contoh tanah lolos saringan nomer 200. Simbol kelompok ini adalah :

$M=$ untuk lanau (silt) anorganik

$C=$ untuk lempung (clay) anorganik

$O=$ untuk lanau-organik dan lempungorganik

$L=$ plastisitas rendah $(\mathrm{LL}<50)$ (low plasticity)

$H=$ plastisitas tinggi (LL > 50) (high plasticity)

Prosedur untuk menentukan klasifikasi tanah Sistem Unified (Hardiyatmo, 2006) adalah sebagai berikut:
1. Tentukan apakah tanah berupa butiran halus atau butiran kasar secara visual atau dengan cara menyaringnya dengan saringan nomer 200.

2. Jika tanah berupa butiran kasar :

a. Saring tanah tersebut dan gambarkan grafik distribusi butiran.

b. Tentukan persen butiran lolos saringan no. 4. Bila persentase butiran yang lolos kurang dari $50 \%$, klasifikasikan tanah tersebut sebagai kerikil. Bila persen butiran yang lolos lebih dari 50\%, klasifikasikan sebagai pasir.

c. Tentukan jumlah butiran yang lolos saringan no.200. Jika persentase butiran yang lolos kurang dari 5\%, pertimbangkan bentuk grafik distribusi butiran dengan menghitung $C u$ da $C c$. Jika termasuk bergradasi baik, maka klasifikasikan sebagai $G W$ (bila kerikil) atau $S W$ (bila pasir). Jika termasuk bergradasi buruk, klasifikasikan sebagai GP (bila kerikil) atau $S P$ (bila pasir). Jika persentase butiran tanah yang lolos saringan no.200 diantara 5 sampai $12 \%$, tanah akan mempunyai simbol dobel dan mempunyai sifat keplastisan ( $G W-G M, S W-S M$, dan sebagainya).

d. Jika persentase butiran yang lolos saringan no.200 lebih besar $12 \%$, harus dilakukan batas-batas Atterberg dengan menyingkirkan 
butiran tanah yang tinggal dalam saringan no.40. Kemudian, dengan menggunakan diagram plastisitas, ditentukan klasifikasinya (GM, $G C, S M, G M-G C$ atau $S M-S C$ ).

3. Jika tanah berbutir halus :

a. Kerjakan uji batas-batas Atterberg dengan menyingkirkan butiran tanah yang tinggal dalam saringan no.40. Jika batas cair lebih dari $50 \%$, klasifikasikan sebagai $H$ (plastisitas tinggi) dan jika kurang dari $50 \%$, klasifikasikan sebagai $L$ (plastisitas rendah).

b. Untuk $H$ (plastisitas tinggi), jika plot batas-batas Atterberg pada grafik plastisitas dibawah garis A, tentukan apakah tanah organik $(\mathrm{OH})$ atau anorganik $(\mathrm{MH})$. Jika plotnya jatuh diatas garis A, klasifikasikan sebagai $\mathrm{CH}$. c. Untuk $L$ (plastisitas rendah), jika plot batas-batas Atterberg pada grafik plastisitas dibawah garis A dan area yang diarsir, tentukan klasifikasi tanah tersebut sebagai organik $(O L)$ atau anorganik $(M L)$ berdasar warna, bau, atau perubahan batas cair dan batas plastisnya dengan mengeringkannya didalam oven.

d. Jika plot batas-batas Atterberg pada grafik plastisitas jatuh pada area yang diarsir, dekat dengan garis A atau nilai $L L$ sekitar 50, gunakan simbol dobel.

Cara menentukan klasifikasi tanah berdasarkan Unified Soil Classification System seperti pada Tabel 2.2 berikut :

Tabel 2.2 Klasifikasi Tanah Sistem USCS

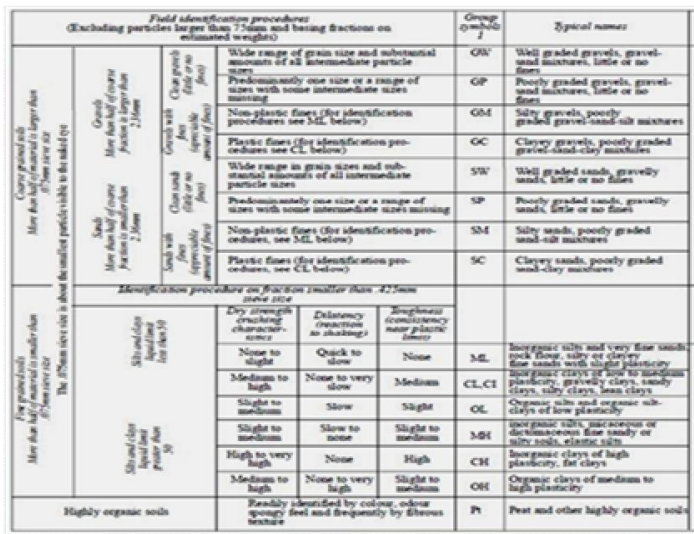

Sumber : Hendarsin (2000)

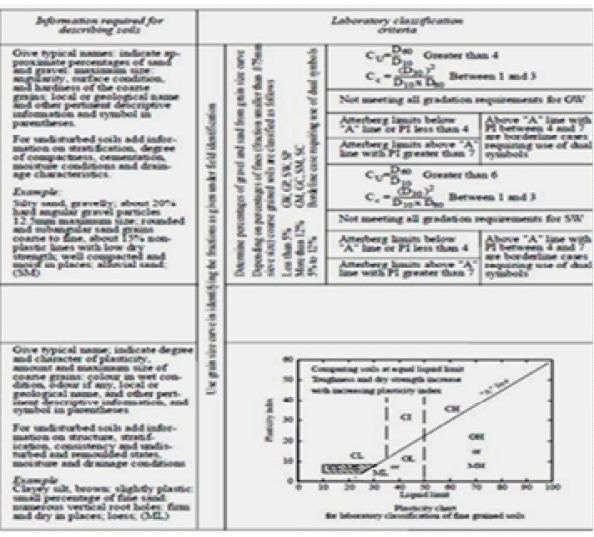

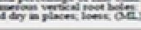

$$
\begin{aligned}
G I= & (F-35)(0,2+0,005(L L-40)+ \\
& 0,01(F-15)(P I-10) \ldots \ldots \ldots \ldots .(2.1)
\end{aligned}
$$

Dengan:

$G I=$ indeks kelompok (group index)

$F=$ persen material lolos saringan no. 200

$L L=$ batas cair

$P I=$ indeks plastisitas

Bila nilai indeks kelompok $(G I)$ semakin tinggi, makin berkurang ketepatan penggunaan tanahnya. Tanah granular diklasifikasikan ke dalam klasifikasi A-1 sampai A-3. tanah A-1 granular yang bergradasi baik, sedang A-3 adalah pasir bersih yang bergradasi buruk. Tanah A-2 termasuk tanah granular (kurang dari 35\% lewat saringan no. 200), tetapi masih terdiri 
atas lanau dan lempung. Tanah berbutir halus diklasifikasikan dari A-4 sampai A-7, yaitu tanah lempung-lanau. Perbedaan keduanya berdasarkan pada batas-batas Atterberg seperti pada Gambar 2.1 berikut :

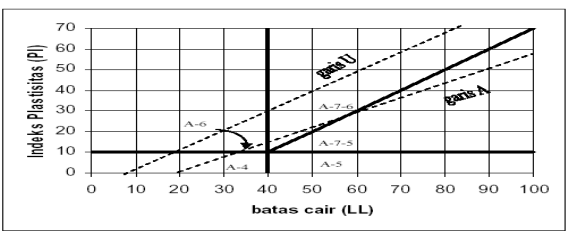

Sumber : Hardiyatmo (1996)
Gambar 2.1 Nilai-nilai Batas-batas Atterberg Untuk Subkelompok A-4, A-5, A-6, dan A-7

Dari Gambar 2.1, dapat digunakan memperoleh batas-batas antara batas cair $(L L)$ dan indeks plastis $(P I)$ untuk kelompok A-4 sampai A-7 dan untuk sub b kelompok dalam A-2. Dalam tanah organik tinggi seperti gambut (peat) diletakan dalam kelompok A-8. Sistem klasifikasi AASHTO, dapat dilihat dalam Tabel 2.3 berikut :

Tabel 2.3 Klasifikasi Tanah Sistem AASHTO

\begin{tabular}{|c|c|c|c|c|c|c|c|c|}
\hline \multirow{3}{*}{$\begin{array}{c}\begin{array}{c}\text { Klasifikasi } \\
\text { umum }\end{array} \\
\begin{array}{l}\text { Klasifikasi } \\
\text { kelompok }\end{array}\end{array}$} & \multicolumn{4}{|c|}{$\begin{array}{c}\text { Material granular } \\
(<35 \% \text { lolos saringan no. 200) }\end{array}$} & \multicolumn{4}{|c|}{$\begin{array}{c}\text { Tanah-tanah lanau-lempung } \\
(>35 \% \text { lolos saringan no. } 200)\end{array}$} \\
\hline & \multirow{2}{*}{\begin{tabular}{|c|}
$\mathrm{A}-1$ \\
$\mathrm{~A}-1-\mathrm{a} \quad \mathrm{A}-1-\mathrm{b}$
\end{tabular}} & \multirow{2}{*}{ A-3 } & \multicolumn{2}{|c|}{ A-2 } & \multirow{2}{*}{ A-4 } & \multirow{2}{*}{ A-5 } & \multirow{2}{*}{ A-6 } & \multirow{2}{*}{$\begin{array}{c}\text { A-7 } \\
\text { A-7-5 } \\
\text { A-7-6 }\end{array}$} \\
\hline & & & A-2-4 A-2-5 & A-2-6 A-2-7 & & & & \\
\hline 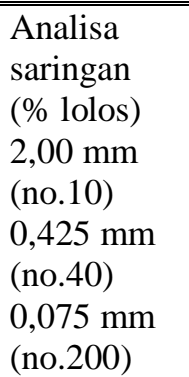 & $\begin{array}{c}50 \text { maks } \\
- \\
30 \text { maks } 50 \\
\text { maks } \\
15 \text { maks } 25 \\
\text { maks }\end{array} \mid$ & $\begin{array}{c}- \\
51 \\
\min \\
10 \\
\text { maks }\end{array}$ & $\begin{array}{c}- \\
- \\
35 \text { maks } \\
\text { maks }\end{array}$ & $\begin{array}{c}- \\
- \\
35 \text { maks } \\
\text { maks }\end{array}$ & $\begin{array}{c}- \\
- \\
35 \\
\min \end{array}$ & $\begin{array}{c}- \\
- \\
36 \\
\text { min }\end{array}$ & $\begin{array}{c}- \\
- \\
36 \\
\min \end{array}$ & $\begin{array}{c}- \\
- \\
36 \mathrm{~min}\end{array}$ \\
\hline $\begin{array}{l}\text { Sifat fraksi } \\
\text { lolos } \\
\text { saringan } \\
\text { no.40 } \\
\text { Bats cair } \\
\text { (LL) } \\
\text { Indeks } \\
\text { plastis (PI) }\end{array}$ & 6 maks & np & $\begin{array}{c}40 \text { maks } 41 \\
\text { min } \\
10 \text { maks } 10 \\
\text { maks }\end{array}$ & $\begin{array}{c}40 \text { maks } 41 \\
\text { min } \\
11 \min 11 \\
\min \end{array}$ & $\begin{array}{c}40 \\
\text { maks } \\
10 \\
\text { maks }\end{array}$ & $\begin{array}{c}41 \\
\min \\
10 \\
\text { maks }\end{array}$ & $\begin{array}{c}40 \\
\text { maks } \\
11 \\
\text { min }\end{array}$ & $\begin{array}{l}41 \mathrm{~min} \\
11 \mathrm{~min}\end{array}$ \\
\hline $\begin{array}{l}\text { Indeks } \\
\text { kelompok } \\
\text { (GI }\end{array}$ & 0 & 0 & 0 & 4 maks & $\begin{array}{c}8 \\
\text { maks }\end{array}$ & $\begin{array}{c}12 \\
\text { maks }\end{array}$ & $\begin{array}{c}16 \\
\text { maks }\end{array}$ & $\begin{array}{c}20 \\
\text { maks }\end{array}$ \\
\hline $\begin{array}{l}\text { Tipe } \\
\text { material } \\
\text { yang } \\
\text { Pokok pada } \\
\text { umumnya }\end{array}$ & $\begin{array}{l}\text { Pecahan } \\
\text { batu } \\
\text { kerikil dan } \\
\text { pasir }\end{array}$ & $\begin{array}{l}\text { Pasir } \\
\text { halus }\end{array}$ & $\begin{array}{r}\text { Kerikil b } \\
\text { berle } \\
\text { dan }\end{array}$ & $\begin{array}{l}\text { rlanau atau } \\
\text { mpung } \\
\text { pasir }\end{array}$ & & ah & & $\begin{array}{l}\text { nah } \\
\text { mpung }\end{array}$ \\
\hline $\begin{array}{l}\text { Penilaian } \\
\text { umum } \\
\text { sebagai } \\
\text { tanah dasar }\end{array}$ & \multicolumn{4}{|c|}{ Sangat baik sampai baik } & \multicolumn{4}{|c|}{ Sedang sampai buruk } \\
\hline
\end{tabular}

Sumber : Hardiyatmo (1996)

Sifat-sifat fisik dari tanah dapat digambarkan dalam fase, seperti ditunjukan pada Gambar 2.2 berikut : 
Isi (Volume)

Berat (Weigth)
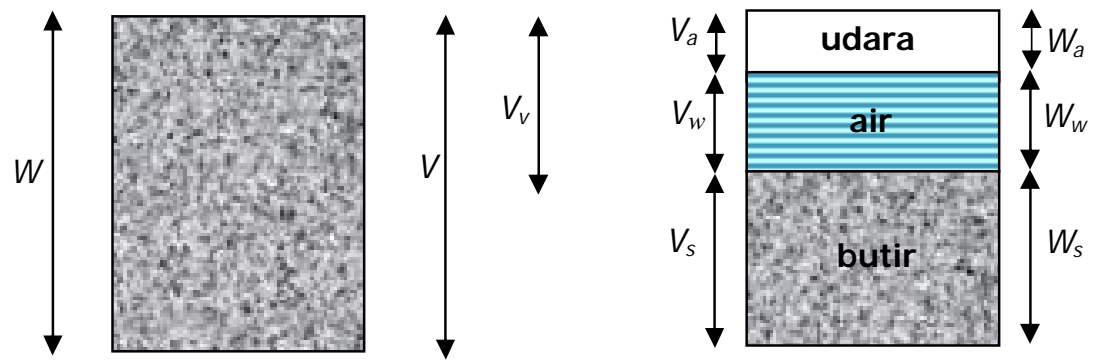

Sumber: Hardiyatmo (1996)

Gambar 2.2 Diagram Fasa Tanah

Dengan:

$W_{s} \quad=$ berat butiran padat

$W_{w} \quad=$ berat air

$V_{s} \quad=$ volume butiran padat

$V_{w} \quad=$ volume air

$V_{a} \quad=$ volume udara

b. Kadar air

Kadar air adalah perbandingan antara berat air dengan berat butiran padat dari volume yang diselidiki dengan Persamaan 2.2 berikut :

Kadar air $(W)=\frac{W_{1}-W_{2}}{W_{2}-W_{3}} \times 100 \%$ (2.2)

c. Berat jenis

Berat jenis (specific gravity) tanah $\left(G_{s}\right)$ didefinisikan sebagai perbandingan berat volume butiran padat $\left(V_{s}\right)$ dengan berat volume air $\left(V_{w}\right)$ pada temperature $40 \mathrm{oC}$ dengan Persamaan 2.3 berikut :

$G_{s}=\frac{V_{s}}{V_{w}}$

Berat jenis dari berbagai jenis tanah berkisar antara 2,65 sampai 2,75 biasanya digunakan

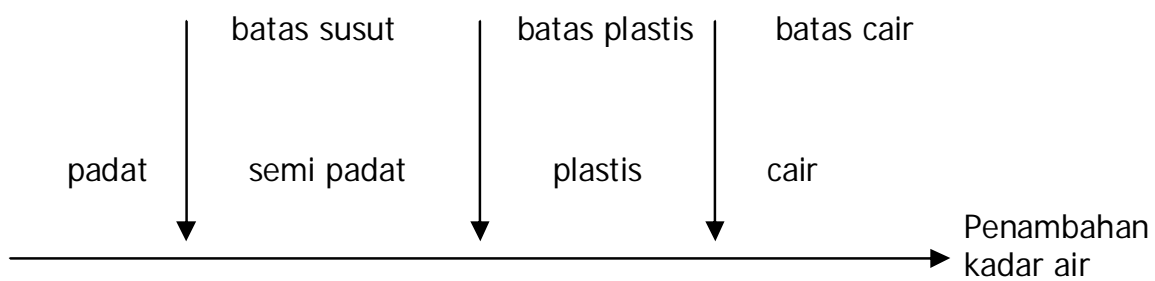

Sumber : Hardiyatmo (1996)

Gambar 2.3 Keadaan-keadaan Konsistensi Tanah 
Cara untuk menggambarkan batas-batas konsistensi dari tanah berbutir halus dengan mempertimbangklan kandungan kadar airnya.

Batas-batas tersebut yaitu :

- Batas Cair (Liquid Limit)

Batas cair $(L L)$, didefinisikan sebagai kadar air tanah pada batas antara keadaan cair dan keadaan plastis, yaitu batas atas dari daerah plastis. Porsentase kadar air dibutuhkan untuk menutup celah sepanjang $12,7 \mathrm{~mm}$ pada dasar cawan, sesudah 25 kali pukulan didefinisikan sebagai batas cair tanah tersebut (Hardiyatmo, 1996).

- Batas Plastis (Plastic Limit).

Batas plastis $(P L)$, didefinisikan sebagai kadar air pada kedudukan antara daerah plastis dan semi padat, yaitu persentase kadar air di mana tanah dengan diameter silinder 3,2 mm mulai retak-retak ketika digulung (Hardiyatmo, 1996).

- Indeks Plastisitas (Plasticity Index)

Indeks plastisitas $(P I)$ adalah selisih batas cair dan batas plastis (Hardiyatmo, 1996) dengan Persamaan 2.4 berikut :

$P I=L L-P L$

Indeks plastisitas merupakan interval kadar air dimana tanah masih bersifat plastis. Batasan mengenai indeks plastis, sifat, macam tanah dan kohesif oleh Atterberg terdapat dalam Tabel 2.5 berikut :

Tabel 2.5 Nilai indeks plastisitas dan macam tanah

\begin{tabular}{|c|l|l|l|}
\hline PI & \multicolumn{1}{|c|}{ Sifat } & \multicolumn{1}{|c|}{ Macam Tanah } & \multicolumn{1}{c|}{ Kohesi } \\
\hline 0 & Non Plastis & Pasir & Non kohesif \\
$<7$ & Plastisitas rendah & Lanau & Kohesif sebagian \\
$7-17$ & Plastisitas rendah & Lempung berlanau & Kohesif \\
$>17$ & Plastisitas tinggi & Lempung & Kohesif \\
\hline
\end{tabular}

Sumber : Hardiyatmo (1996)

Menurut Hicks (2002), distribusi ukuran butir dan batas-batas Atterberg digunakan sebagai dasar penilaian macam stabilisasi yang akan digunakan, seperti yang ditunjukkan pada Tabel 2.6 berikut :

Tabel 2.6 Petunjuk Awal Untuk Pemilihan Metode Stabilisasi.

\begin{tabular}{|c|c|c|c|c|c|c|}
\hline $\begin{array}{c}\text { Material lolos } \\
\text { Saringan no.200 } \\
\end{array}$ & \multicolumn{3}{|c|}{$\begin{array}{l}>25 \% \text { lolos saringan } \\
\text { No. } 200(0,075 \mathrm{~mm})\end{array}$} & \multicolumn{3}{|c|}{$\begin{array}{l}<25 \% \text { lolos saringan } \\
\text { No. } 200(0,075 \mathrm{~mm}) \\
\end{array}$} \\
\hline $\begin{array}{c}\text { Indeks } \\
\text { Plastisitas } \\
\text { PI (\%) }\end{array}$ & $\leq 10$ & $10-20$ & $\geq 20$ & $\begin{array}{c}\leq 6(P I x \\
\text { persen lolos } \\
\text { saringan } \\
\text { no. } 200 \leq 6)\end{array}$ & $\leq 10$ & $\geq 10$ \\
\hline \multicolumn{7}{|l|}{ Bentuk stabilisasi : } \\
\hline $\begin{array}{l}\text { Semen dan } \\
\text { campuran } \\
\text { pengikat }\end{array}$ & Cocok & Ragu & $\begin{array}{l}\text { Tidak } \\
\text { cocok }\end{array}$ & Cocok & Cocok & Cocok \\
\hline Kapur & Ragu & Cocok & Cocok & $\begin{array}{l}\text { Tidak } \\
\text { cocok }\end{array}$ & Ragu & Cocok \\
\hline Aspal (bitumen) & Cocok & Ragu & $\begin{array}{l}\text { Tidak } \\
\text { cocok }\end{array}$ & Cocok & Cocok & Ragu \\
\hline $\begin{array}{l}\text { Aspal/semen } \\
\text { dicampur }\end{array}$ & Cocok & Ragu & $\begin{array}{l}\text { Tidak } \\
\text { cocok }\end{array}$ & Cocok & Cocok & Ragu \\
\hline Granular & Cocok & $\begin{array}{l}\text { Tidak } \\
\text { cocok }\end{array}$ & $\begin{array}{l}\text { Tidak } \\
\text { cocok }\end{array}$ & $\begin{array}{l}\text { Tidak } \\
\text { cocok }\end{array}$ & Cocok & Ragu \\
\hline $\begin{array}{l}\text { Lain-lain } \\
\text { campuran }\end{array}$ & $\begin{array}{l}\text { Tidak } \\
\text { cocok }\end{array}$ & Cocok & Cocok & $\begin{array}{l}\text { Tidak } \\
\text { cocok }\end{array}$ & Ragu & Cocok \\
\hline
\end{tabular}

Sumber : Hardiyatmo ( 2010) 
Petunjuk dari Tabel 2.6 hanya sebagai pertimbangan awal, dan dapat digunakan untuk maksud modifikasi tanah, seperti: stabilisasi dengan kapur untuk membuat material lebih kering dan mengurangi plastisitasnya.

\section{Sifat-sifat Mekanik Tanah}

Sifat Mekanik Tanah yaitu perilaku tanah akibat diberikannya gaya terhadap tanah yang meliputi kuat geser tanah, sudut geser dalam, nilai kohesi tanah dan lain-lain.

\section{a. Pengujian Pemadatan}

Pemadatan adalah suatu proses memadatnya partikel tanah sehingga terjadi pengurangan volume udara dan volume air dengan memakai cara mekanis. Kepadatan tanah tergantung banyaknya kadar air, jika kadar air tanah sedikit maka tanah akan keras begitu pula sebaliknya bila kadar air banyak maka tanah akan menjadi lunak atau cair. Pemadatan yang dilakukan pada saat kadar air lebih tinggi daripada kadar air optimumnya akan memberikan pengaruh terhadap sifat tanah. Tujuan pemadatan tanah adalah memadatkan tanah pada kadar air optimum dan memperbaiki karakteristik mekanisme tanah. Maksud pemadatan tanah (Hardiyatmo, 1996) adalah sebagai berikut:
1. Mempertinggi kuat geser tanah.

2. Mengurangi sifat mudah mampat (kompresibilitas).

3. Mengurangi permeabilitas.

4. Mengurangi perubahan volume sebagai akibat perubahan kadar air.

Pemadatan tanah dapat dilaksanakan di lapangan maupun di laboratorium. Dilapangan biasanya tanah akan digilas dengan mesin penggilas yang didalamnya terdapat alat penggetar, getaran akan menggetarkan tanah sehingga terjadi pemadatan. Sedangkan dilaboratorium menggunakan pengujian ringan (standart), yang disebut dengan uji Proctor, dengan cara suatu palu dijatuhkan dari ketinggian tertentu beberapa lapisan tanah di dalam sebuah mold. Dengan dilakukannya pengujian pemadatan tanah ini, maka akan terdapat hubungan antara kadar air dengan berat volume. Derajat kepadatan tanah diukur dari berat volume keringnya, hubungan berat volume kering $\left(\gamma_{d}\right)$, berat volume basah $\left(\gamma_{b}\right)$ dan kadar air $(w)$ dinyatakan dengan Persamaan 2.5 dan Gambar 2.4 berikut :

$$
\gamma_{d}=\frac{\gamma_{b}}{1+w}
$$

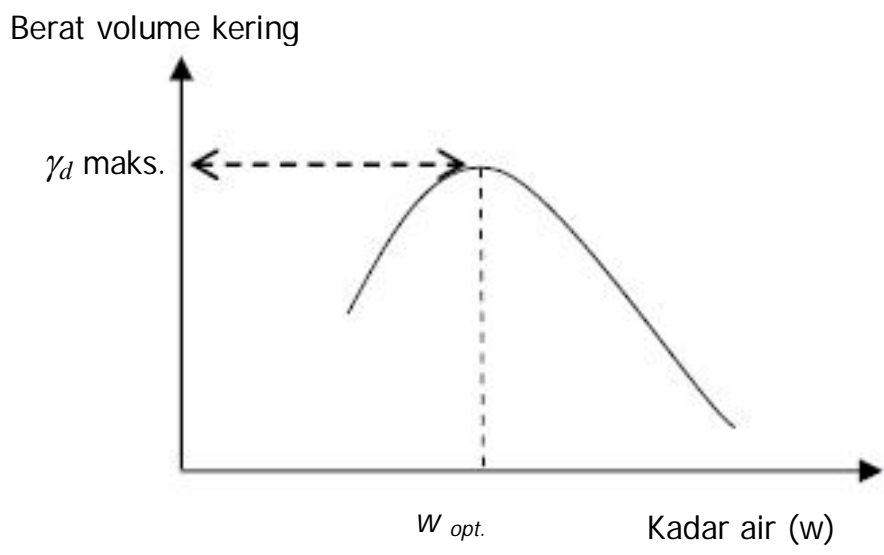

Sumber : Hardiyatmo (1996)

Gambar 2.4 Hubungan Antara Kadar Air dan Berat Volume Tanah $\left(\gamma_{d}\right.$ maks)

Untuk mengetahui kadar air yang optimum pada tanah, maka dilakukan pengujian pemadatan, pengujian tersebut dilakukan dengan pemadatan sampel tanah basah (pada kadar air terkontrol) dalam suatu cetakan dengan jumlah lapisan tertentu. Setiap lapisan dipadatkan dengan sejumlah tumbukan yang ditentukan dengan penumbuk dengan massa dan tinggi jatuh tertentu. Apabila diketahui berat tanah basah didalam cetakan yang volumenya diketahui, maka berat isi basah dapat langsung dihitung dengan Persamaan 2.6 berikut : 


$$
\gamma_{b}=\frac{W_{w}+W_{s}}{V}
$$

$\gamma$ basah adalah perbandingan berat tanah basah dalam cetakan dengan volume cetakan, kadar air diperoleh dari tanah yang dipadatkan. Untuk tanah berbutir halus dalam mendapatkan kadar air optimum digunakan batas plastisnya. Buat kurva hubungan antara kadar air (w) sebagai absis dan berat volume tanah kering sebagai ordinat, puncak kurva sebagai nilai $\gamma_{d}$ (maksimun), kurva yang digunakan adalah kurva dari uji pemadatan tanah (Proctor). Dari titik puncak dit ditarik garis vertikal memotong absis, pada titik ini adalah kadar air optimum seperti pada Gambar 2.5 berikut :

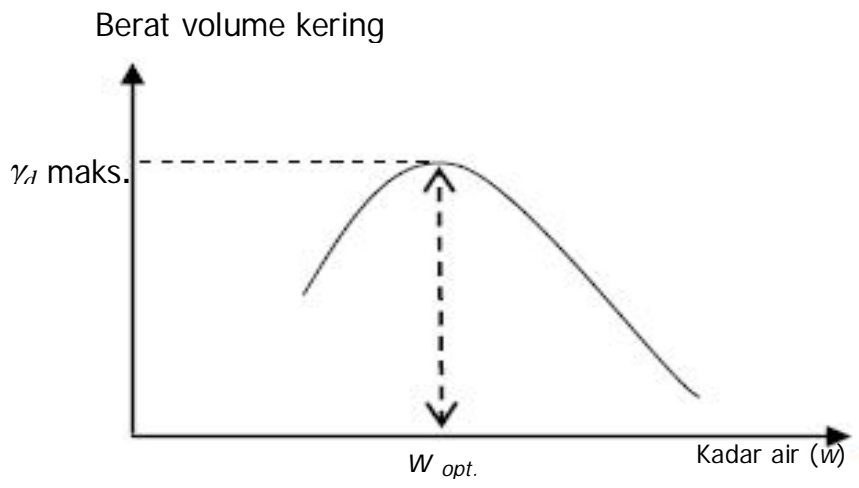

Sumber : Hardiyatmo (1996)

Gambar 2.5 Hubungan Antara Kadar Air dan Berat Volume Tanah(kadar air optimum)

\section{b. Uji Kuat Tekan Bebas (UCS)}

Pengujian ini merupakan cara dilakukan di laboratorium untuk menghitung kekuatan geser tanah. Uji kuat tekan bebas ini mengukur seberapa kuat tanah menerima kuat tekan yang diberikan sampai sampel tanah berbentuk silinder yang bebas bagian sampingnya tersebut terpisah dari butiran-butirannya (pecah) juga mengukur regangan tanah akibat tekanan. Pengujian kuat tekan ini dilakukan pada tanah asli dan juga pada tanah yang sudah diberi campuran semen. Namun untuk tanah yang sudah diberi campuran semen, pengujian dilaksanakan pada waktu peram 7 hari. Pembacaan tegangan pada pengujian kuat tekan bebas ini dibatasi sampai regangan $20 \%$. Adapun perhitungan untuk uji kuat tekan bebas dengan Persamaan 2.7 berikut :

$$
\begin{gathered}
\text { Regangan axial }: \varepsilon=\frac{\Delta L}{L_{o}} \ldots \ldots \ldots . . . . \\
\varepsilon=\text { regangan axial } \\
\Delta L=\text { perubahan panjang } \\
L_{o}=\text { Panjang contoh awal }
\end{gathered}
$$

\section{c. Uji California Bearing Ratio (CBR)}

Nilai CBR adalah perbandingan (dalam persen) antara tekanan yang diperlukan untuk menembus tanah dengan piston berpenampang bulat seluas 3 inch dengan kecepatan 0,05 inch/menit terhadap tekanan yang diperlukan untuk menembus bahan standard tertentu. Untuk menentukan kekuatan lapisan tanah dasar dengan cara percobaan $C B R$ diperoleh nilai yang kemudian dipakai untuk menentukan tebal perkerasan yang diperlukan di atas lapisan yang nilai $C B R$ nya tertentu. Dalam menguji nilai $C B R$ tanah dapat dilakukan di laboratorium. Tanah dasar (Subgrade) pada kontruksi jalan baru merupakan tanah asli, tanah timbunan, atau tanah galian yang sudah dipadatkan sampai mencapai kepadatan 95\% dari kepadatan maksimum. Dengan demikian daya dukung tanah dasar tersebut merupakan nilai kemampuan lapisan tanah memikul beban setelah tersebut tanah dipadatkan. $C B R$ ini disebut $C B R$ rencana titik dan karena disiapkan di laboratorium, disebut $C B R$ laborataorium. Makin tinggi nilai $C B R$ tanah (subgrade) maka lapisan perkerasan diatasnya akan semakin tipis dan semakin kecil nilai $C B R$ (daya dukung tanah rendah), maka akan semakin tebal lapisan perkerasan di atasnya sesuai beban yang akan dipikulnya. 
Ada 2 macam pengukuran $C B R$ yaitu :

1. Nilai $C B R$ untuk penekanan pada penetrasi $0,254(0,1 ")$ terhadap penetrasi standar yang besarnya $70,37 \mathrm{~kg} / \mathrm{cm}^{2}$ (1000 psi) dengan Persamaan 2.8 berikut :

$$
C B R=\frac{P_{1}}{70,37} \times 100 \%\left(\mathrm{~kg} / \mathrm{cm}^{2}\right) \text {. }
$$

2 Nilai $C B R$ untuk tekanan pada penetrasi $0,508(0,2 ")$ terhadap tekanan standar yang besarnya $105,56 \mathrm{~kg} / \mathrm{cm}^{2}$ (1500 psi) dengan Persamaan 2.9 berikut :

$$
C B R=\frac{P_{2}}{105,56} \times 100 \%\left(\mathrm{~kg} / \mathrm{cm}^{2}\right) .
$$

\section{STUDI PUSTAKA}

Penelitian-penelitian tentang stabilisasi tanah semen telah banyak dilakukan sebelumnya lainya, seperti yang dilakukan oleh :

a. Bambang R (2014) melakukan penelitian judul "Peningkatan Nilai Kuat Tekan Bebas (UCS) Tanah Yang Distabilisasi dengan Semen sebagai Lapis Pondasi Atas". Dari hasil penelitian untuk perbaikan tanah dicampur dengan semen sangat berpengaruh terhadap kuat tekan bebas (UCS) dari tanah asli 3,481 $\mathrm{kg} / \mathrm{cm}^{2}$ setelah distabilisasi dengan semen meningkat sangat signifikan menjadi $U_{C S_{7 h r}}$ minimum $19,811 \mathrm{~kg} / \mathrm{cm}^{2}$ dengan kadar semen $5 \%$ dan maksimum $37,559 \mathrm{~kg} / \mathrm{cm}^{2}$ dengan kadar semen $12 \%, U C S_{14 h r}$ minimum 20,473 $\mathrm{kg} / \mathrm{cm}^{2}$ dengan kadar semen $5 \%$ dan maksimum $47,465 \mathrm{~kg} / \mathrm{cm}^{2}$ dengan kadar semen $12 \%$.

b. I Gusti Ayu I. L (2014), melakukan penelitian dengan judul : "Karakteistik Tanah Lempung Ekspansif (Studi Kasus di Desa Tanah Awuk, Lobok Tengah)". Tanah lempung ekspansif Tanah Awuk memeliki kadar air rata-rata sebesar 47,50\%, berat jenis 2,71, batas cair $125,84 \%$, batas plastis $28,45 \%$, batas susut 9,88\% dan indeks plastisitas 97,39\% dengan klasisikasi AASTHO merupakan tanah berjenis sedang sampai buruk sedangkan klasifikasi USCS merupakan tanah lempung dengan plastisitas tinggi $(\mathrm{CH})$. Uji pemadatan pada kedalaman 0,6 meter kadar air optimum $20,34 \%$, berat volume kering $1,37 \mathrm{gr} / \mathrm{cm}^{3}$ dan kedalaman 1,2 meter kadar air optimum $29,43 \%$, berat volume kering $1,34 \mathrm{gr} / \mathrm{cm}^{3}$.

\section{METODE PENGUJIAN}

\section{Tahapan Pengujian}

Pengujian dilakukan terhadap tanah lokal quari desa Bukit Batu dan dusun Manyawang dalam kondisi terganggu (disturbed). Tahapan pengujian dilaksanakan sesuai dengan bagan alir seperti pada Gambar 3.1 berikut :

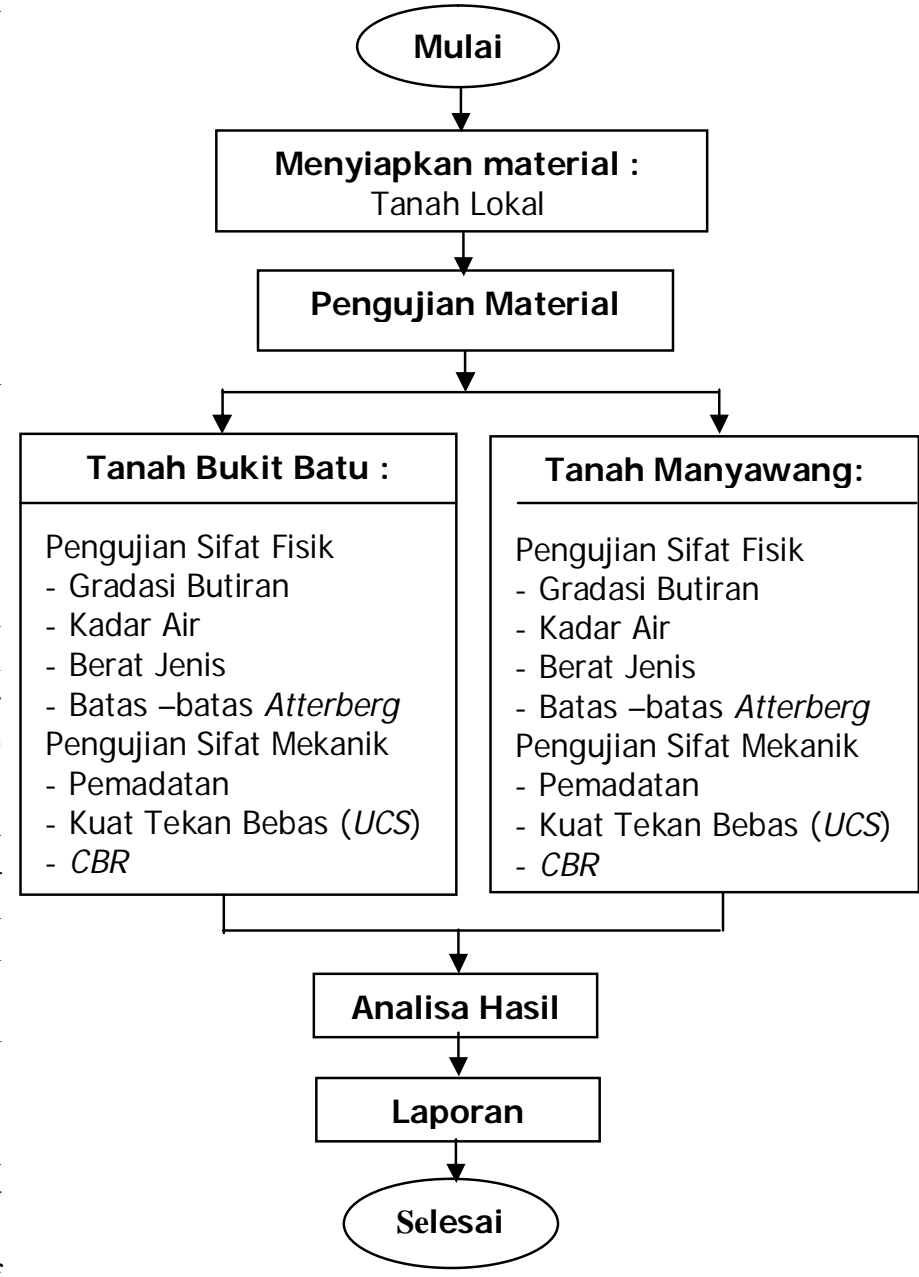

Gambar 3.1 Diagram Alir Tahapan Pengujian

\section{HASIL PENGUJIAN DAN PEMBAHASAN}

Dalam penelitian ini mengulas tentang pengujian sifat-sifat fisik dan mekanik tanah quari desa Bukit Batu dan dusun Manyawang dalam kondisi terganggu (disturbe) yang memenuhi syarat agar bisa digunakan sebagai material stabilisasi dengan semen. Dalam pengambilan sampel tanah 
quari desa Bukit Batu sedalam 1,5 meter dari muka tanah dengan warna tanah kuning kecoklatan dan quari dusun Manyawang 1,25 meter dari muka tanah dengan warna tanah kuning kecoklatan.

\section{Sifat-sifat Fisik Tanah}

\section{a. Kadar Air}

Dari kedua sampel untuk uji kadar air tanah quari dusun Manyawang 13,80\% < 14,34\% quari desa Bukit Batu.

b. Berat Jenis
Dari kedua sampel untuk uji berat jenis tanah quari dusun Manyawang 2,635 < 2,637 quari desa Bukit Batu. Berdasarkan Tabel 2.4, tanah kedua quari ini termasuk katagori lanau anorganic dan lempung organic.

\section{c. Analisa Saringan}

Gradasi ukuran butir material tanah sangat penting dan salah satu faktor yang mempengaruhi terhadapat kekuatan. Berdasarkan hasil analisis uji distribusi yang plot dalam satu grafik logaritmik terlihat tren persentasi dari ukuran butir material yang seperti pada Gambar 3.1 berikut :

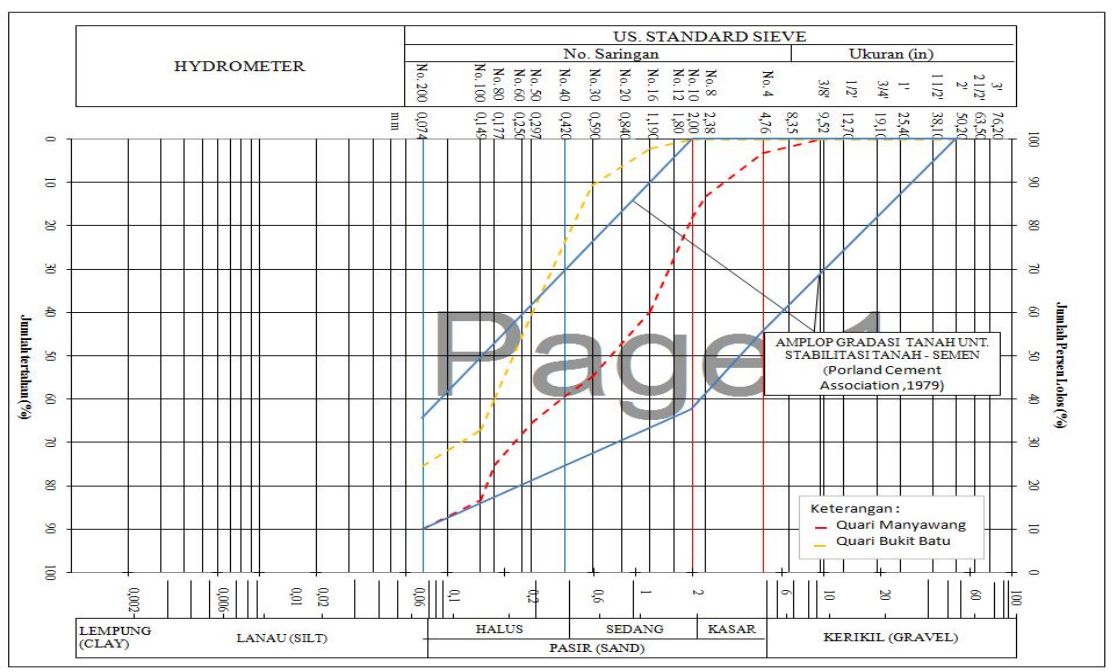

Gambar 3.1 Hasil Uji Distribusi Ukuran Butir Material Tanah

Dari hasil pengujian distribusi ukuran butir tanah dapat dilihat pada Gambar 3.1 menunjukan material untuk pekerjaan Lapis Pondasi Tanah Semen dari quari dusun Manyawang memenuhi persyaratan yang di ijinkan (Porland Cement Association ,1979 dan
Spesifikasi Umum 2010, revisi 3) sedangkan quari desa Bukti Batu hanya memenuhi persyaratan Spesifikasi Umum 2010, revisi 3, dengan komposisi ukuran butiran dapat di lihat pada Tabel 3.4 adalah sebagai berikut :

Tabel 3.4 Hasil Gradasi Material Tanah

\begin{tabular}{|l|l|c|c|}
\hline \multirow{2}{*}{ No. } & \multicolumn{1}{|c|}{ Uraian } & \multicolumn{2}{|c|}{ Jumlah Persen (\%) } \\
\cline { 3 - 4 } & & Bukit Batu & Manyawang \\
\hline \hline & & & \\
1 & Agregat Kasar & 0 & 3,11 \\
2 & Agregat Sedang & 23,85 & 56,27 \\
3 & Agregat Halus & 51,42 & 30,52 \\
4 & Tertahan \# 200 & 26,79 & 20,42 \\
5 & Lolos \# 200 & 24,79 & 10,10 \\
\hline
\end{tabular}

d. Batas-batas Atterberg

material tanah lokal dapat di lihat pada Tabel 3.5 adalah sebagai berikut : 
Tinjauan Karakterisik Tanah untuk Stabilisasi..., Bambang Raharmadi

Dari analisis pengujian batas-batas Atterberg

Tabel 3.5 Batas-batas Atterberg Material Tanah

\begin{tabular}{|c|c|c|c|c|}
\hline \multirow{2}{*}{ No. } & \multirow{2}{*}{ Pengujian } & \multicolumn{2}{|c|}{ Jumlah Persen (\%) } & \multirow{2}{*}{ Hicks ,2002 } \\
\cline { 3 - 4 } & & Bukit Batu & Manyawang & \\
\hline & & & & \\
1. & Batas Cair & 20,90 & 24,60 & \\
2. & Batas Plastis & 15,49 & 18,39 & \\
3. & Indeks Plastisitas & 5,41 & 6,21 & $<10$ \\
\hline
\end{tabular}

Hasil dari pengujian Batas Cair diplot dalam grafik didapat hasil seperti Gambar 3.2 sebagai berikut :

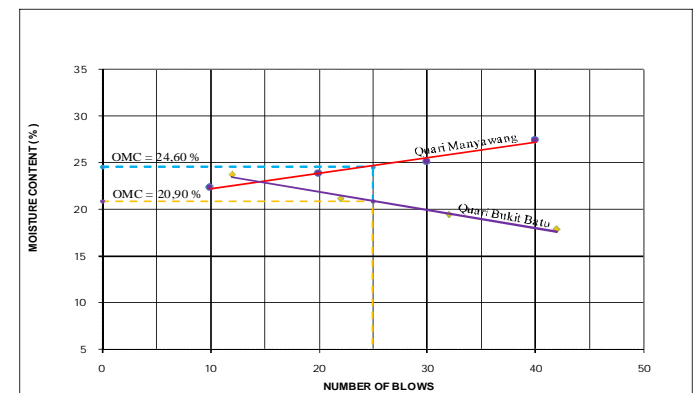

Gambar 3.2 Hasil Pengujian Batas Cair Material Tanah

Berdasarkan penguian batas-batas Atterberg dari quari desa Bukit Batu indeks plastisitas $5,41 \%$ dan quari dusun Manyawang indeks plastisitas $6,21 \% \leq 10 \%$ cocok digunakan sebagai stabilitasi dengan semen memenuhi syarat yang ditentukan (Hicks 2002). dan termasuk golongan plastisitas rendah.

Klasifikasi Tanah Sistem USCS berdasarkan hasil batas cair $(L L)$ dan indeks plastisitas $(P I)$, yang diplotkan dengan diagram plastisitas, quari desa Bukit Batu dan dusun Manyawang termasuk pada kelompok $C L-M L$ yaitu lanau tak organik, lempung kepasiran dengan plastisitas rendah dapat dilihat pada Gambar 3.3 berikut :

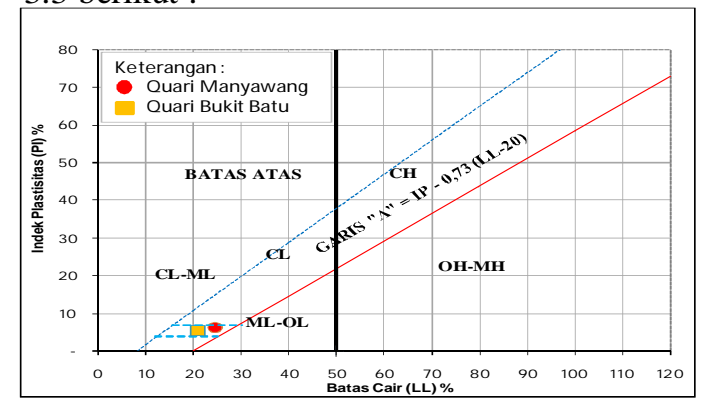

Sumber : Hendarsin (2000)

Gambar 3.3 Diagram Plastisitas Tanah Berbutir Halus Sistem USCS
Berdasarkan Klasifikasi Tanah Sistem AASHTO dan hasil pengujian batas cair $(L L)$ serta indek plastisitas $(P I)$, yang diplotkan dengan diagram plastisitas, quari desa Bukit Batu dan dusun Manyawang termasuk pada kelompok $A-4$ yaitu lempung lanau dengan plastisitas rendah dapat dilihat pada Gambar 3.4 berikut :

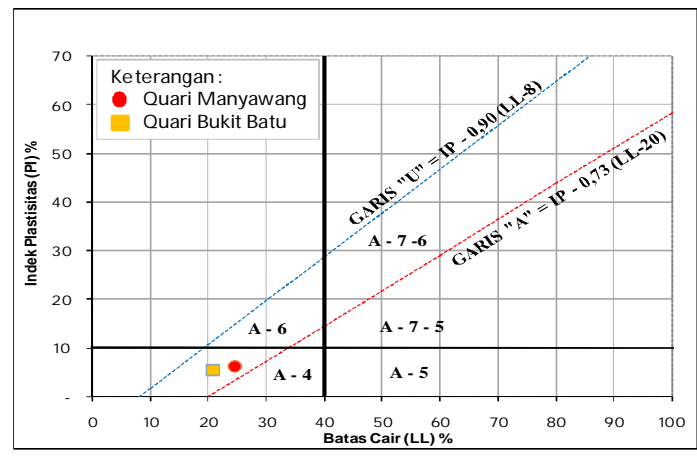

Sumber : Hardiyatmo (1996)

Gambar 3.4 Nilai-nilai Batas-Batas Atterberg untuk Subkelompok A-4, A-5,A6 dan A-7

\section{Sifat-sifat Mekanik Tanah}

a. Uji Pemadatan

Hasil uji pemadatan ringan (standart) diperoleh data seperti pada Tabel 3.6 berikut :

Tabel 3.6 Hasil Pengujian Pemadatan Ringan Tanah

\begin{tabular}{|c|c|c|c|}
\hline \multirow{2}{*}{ No. } & Pengujian & $\begin{array}{c}\text { Hasil Pengujian } \\
\text { Batu }\end{array}$ & Manyawang \\
\hline \hline \multicolumn{2}{|c|}{$\begin{array}{l}\text { Berat isi kering } \\
\text { 2. }\end{array}$} & 1,860 & 1,855 \\
$\begin{array}{c}\text { Kadar air optimum } \\
(\%)\end{array}$ & 13,3 & 13,0 \\
\hline
\end{tabular}

Berdasarkan hasil uji pemadatan ringan tanah dapat diplotkan dalam satu grafik hubungan antara berat isi kering maksimum $\left(\gamma_{\text {dmax }}\right)$ dan kadar air 
Tinjauan Karakterisik Tanah untuk Stabilisasi..., Bambang Raharmadi

optimum $\left(W_{\text {opt }}\right)$ didapat seperti pada Gambar 3.5 berikut :

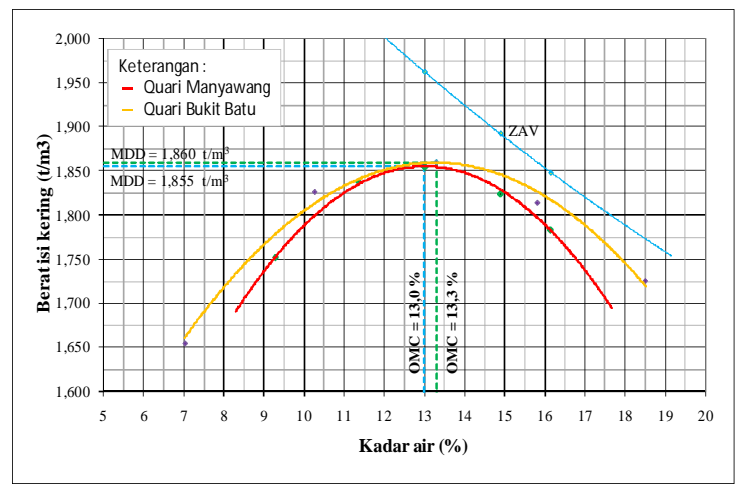

Gambar 3.5 Hubungan Kadar Air dengan Berat Isi Kering

\section{b. Uji Kuat Tekan Bebas (UCS)}

Berdasarkan hasil uji $U C S$ tanah quari dusun Manyawang 3,521 $(\mathrm{kg} / \mathrm{cm} 2)>3,451(\mathrm{~kg} / \mathrm{cm} 2)$ quari desa bukit batu. Perbandingan hasil uji UCS antara kedua quari tesebut diplotkan dalam grafik seperti pada Gambar 3.6 berikut

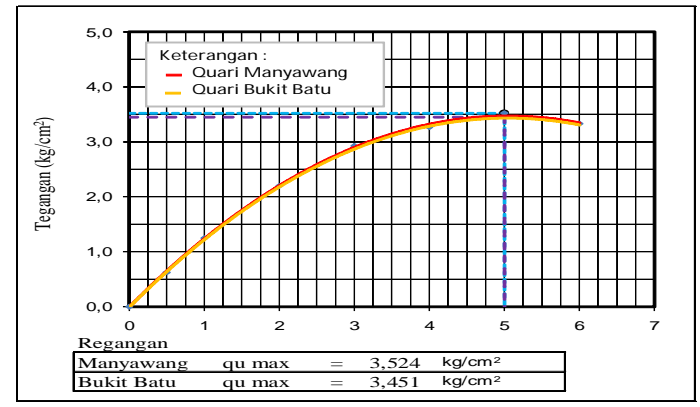

Gambar 3.6 Hasil Uji Kuat Tekan Bebas Tanah

c. Uji California Bearing Ratio (CBR)

Berdasarkan hasil uji pemadatan standart dan uji $C B R$ tanah quari dusun Manyawang $C B R \quad 100 \quad 9,40 \%$ $>8,10 \%$ quari desa bukit batu dan quari dusun Manyawang $C B R 95$ $5,20 \%>4,65 \%$ quari desa Bukit Batu. Perbandingan hasil uji antara kedua quari tesebut diplotkan dalam grafik seperi pada Gambar 3.7 berikut :
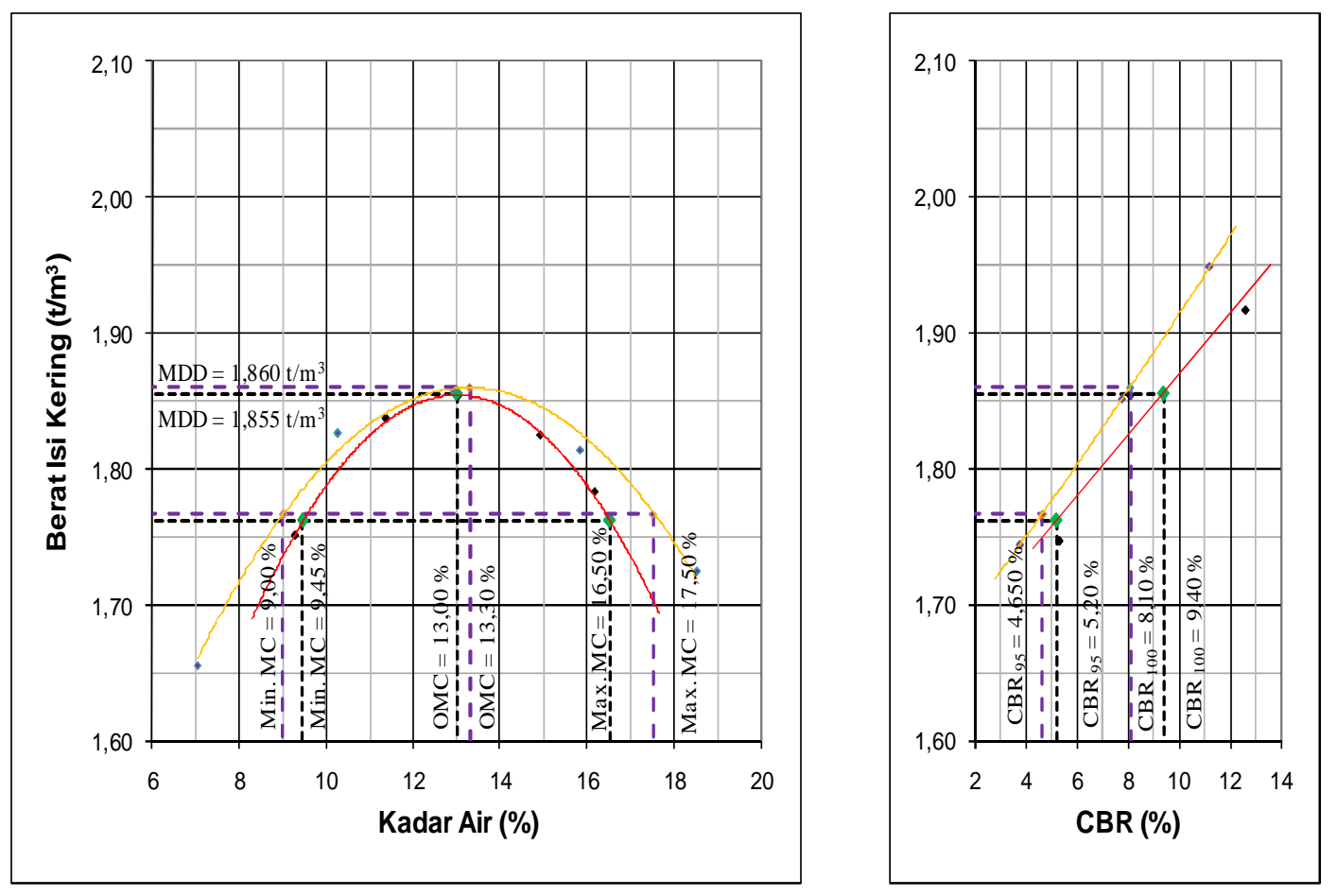

Gambar 3.7 Hubungan Hasil Uji Pemadatan dan CBR Tanah 


\section{PENUTUP}

\section{Kesimpulan}

Berdasarkan hasil analisis dalam penyusunan penelitian ini, maka dapat simpulkan antara lain :

1. Sampel tanah quari desa Bukit Batu sedalam 1,5 meter dari muka tanah dengan warna tanah kuning kecoklatan, kadar air $14,34 \%$, berat jenis 2,637 dan quari dusun Manyawang 1,25 meter dari muka tanah dengan warna tanah kuning kecoklatan, kadar air $13,80 \%$, berat jenis 2,635. Tanah kedua quari tersebut berdasarkan berat jenis dikatagori lanau anorganic dan lempung organic.

2. Uji distribusi ukuran butir tanah quari desa Bukit Batu dan Manyawang memenuhi syarat yang diijinkan untuk digunakan sebagai material stabilisasi tanah semen dengan indek plastisitas $5,41 \%, 6,21 \% \leq 10 \%$ syarat yang ditentukan (Hicks,2002) dan klasifikasi tanah sistem USCS termasuk pada kelompok $C L-M L$ yaitu lanau tak organik, lempung kepasiran dengan plastisitas rendah dan AASHTO termasuk pada kelompok $A-4$ yaitu lempung lanau dengan plastisitas rendah.

3. Uji pemadatan ringan (standart) quari desa Bukit Batu isi kering maksimum $\left(\gamma_{\text {dmax }}\right)$ dari tanah $1,860 \mathrm{t} / \mathrm{m}^{3}$, kadar air optimum 13,30\% dan Manyawang berat berat isi kering maksimum $\left(\gamma_{\text {dmax }}\right)$ dari tanah1,860 $\mathrm{t} / \mathrm{m}^{3}$, kadar air optimum 13,30\%.

4. Uji kuat tekan bebas (UCS) quari desa Bukit Batu dan Manyawang 3,451 kg/ $\mathrm{cm}^{2}, \quad 3,521$ $\mathrm{kg} / \mathrm{cm}^{2}$.

5. Uji $C B R$ quari desa Bukit Batu dan Manyawang $C B R{ }_{100} 9,40 \%, 8,10 \%$ dan $C B R$ $955,20 \%, 4,65$.

6. Dari hasil pengujian sifat-sifat fisik dan mekanik kedua quari tersebut memenuhi persyaratan sebagai material untuk lapis pondasi tanah semen.

\section{Saran}

Berdasarkan kesimpulan dari penyusunan penelitian ini, maka di saran sebagai berikut :

1. Dianjurkan untuk lapis pondasi tanah semen material tanah yang ideal harus berbutir (laterit) atau tanah kepasiran dan sirtu ini lebih ekonomis ditinjau dari segi kadar semen.
2. Jarak quari ke lokasi pekerjaan diperhitungkan dan metode pelaksanaan mana yang lebih menguntungkan dengan pencampuran di quari (pugmill) atau di lokasi pekerjaan (soil stabilizer).

\section{DAFTAR PUSTAKA}

Badan Standar Nasional, (2008). Cara Uji Penentuan Kadar Air Untuk Tanah Dan Batuan Dilaboratorium (SNI 1965-2008). Jakarta

Badan Standar Nasional, (2008). Cara Uji Penentuan Batas Cair Tanah (SNI 19672008). Jakarta

Badan Standar Nasional, (2008). Cara Uji Berat Jenis Tanah (SNI 1964-2008). Jakarta

Badan Standar Nasional, (2008). Cara Uji Penentuan Batas Plastisitas dan Indeks Plastisitas Tanah (SNI 1966-2008). Jakarta

Badan Standar Nasional, (2008). Cara Uji Analisis Butir Tanah (SNI 3423-2008). Jakarta

Badan Standar Nasional, (2089). Cara Uji Kepadatan Ringan Untuk Tanah (SNI 031742-1989). Jakarta

Badan Standar Nasional, (1989). Metode Pengujian CBR Laboratorium (SNI 031744-1989). Jakarta

Badan Standar Nasional, (1994). Metode pengujian kuat tekan bebas tanah kohesif (SNI 03-3638-1994). Jakarta

Das. (2008). Advanced Soil Mechanics. Third Edition. Publishing by Taylor \& Francis. New York, U.S.A

I Gusti Ayu I. L (2014) Karakteristik Tanah Lempung Ekspansif (Studi Kasus di Desa Awuk, Lombok Tengah. Fakultas Teknik Universitas Islam Al-Azhar Mataram. Gane C. Swara Vol. 8 no. 2 September 2014

Hardiyatmo, H.C, (2010), Stabilisasi Tanah Untuk Perkerasan Jalan, Gajah Mada University Press, Yogyakarta. 
Tinjauan Karakterisik Tanah untuk Stabilisasi..., Bambang Raharmadi

Hardiyatmo, HC, (2006), Mekanika Tanah 1, Edisi Keempat, Gajah Mada University Press, Yogyakarta.

Hendarsin, (2000). Perencanaan Teknik Jalan Raya. Penerbit Politeknik Negeri Bandung

R, Bambang (2014) Peningkatan Nilai Kuat Tekan Bebas (UCS) Tanah Yang Distabilisasi dengan Semen sebagai Lapis Pondasi Atas. Jurnal Program Studi Teknik Sipil Fakultas Teknik Universitas Palangka Raya ISSN 1979-6676 Januari 2014

Pusat Litbang Prasarana Transportasi Badan Penelitian dan Pengembangan Kementerian Pekerjaan Umum, (2015). Spesifikasi Umum 2010 revisi 3. Jakarta 